\title{
Dynamic Economic Dispatch Mempertimbangkan Demand Response Menggunakan Particle Swarm Optimization
}

\author{
Zico Musiano Sihombing, Rony Seto Wibowo, dan Ni Ketut Aryani \\ Departemen Teknik Elektro, Fakultas Teknologi Elektro, Institut Teknologi Sepuluh Nopember (ITS) \\ e-mail: ketut.aryani@gmail.com
}

\begin{abstract}
Abstrak - Seiring berkembangnya zaman, permintaan daya listrik pun terus mengalami peningkatan, peningkatan ini dapat terjadi karena jumlah penduduk yang semakin hari semakin bertambah. Biaya bahan bakar juga semakin meningkat yang menyebabkan biaya pembangkitan tenaga listrik juga akan mengalami peningkatan. Oleh karena itu dibutuhkan suatu optimasi pada energi listrik tersebut, mengingat listrik sudah menjadi kebutuhan utama bagi manusia. Optimasi pada pembangkit tenaga listrik merupakan suatu proses untuk mendapatkan kombinasi daya output dari generator, yang dapat menghasilkan biaya pembangkitan yang minimal. Dynamic Economic Dispatch (DED) merupakan salah satu teknik optimasi pada pembangkit tenaga listrik, dimana DED digunakan untuk menentukan kombinasi daya output pada tiaptiap generator pada setiap periodenya (24 jam). Demand Response Program (DRP) merupakan salah satu faktor yang dapat mempengaruhi biaya pembangkitan tenaga listrik, karena DRP digunakan untuk mengurangi permintaan beban pada suatu periode tertentu. Pada tugas akhir ini, metode DRP yang digunakan adalah Emergency Demand Response / Direct Load Control (EDRP/DLC). EDRP/DLC termasuk ke dalam incentive-based demand response program. Untuk menyelesaikan permasalahan ini, penulis akan menggunakan metode particle swarm optimization (PSO).
\end{abstract}

Kata Kunci-dynamic economic dispatch, demand response, incentive-based demand response program, particle swarm optimization.

\section{PENDAHULUAN}

K EBUTUHAN akan energi listrik terus meningkat, hal ini disebabkan oleh jumlah penduduk yang terus bertambah. Oleh karena itu, dibutuhkan suatu optimasi pada energi listrik tersebut, agar supaya energi listrik tersebut dapat dimanfaatkan dengan baik, dan juga mengingat listrik merupakan salah satu hal yang sangat penting didalam kehidupan manusia. Economic Dispatch (ED) merupakan salah satu teknik optimisasi dalam power system [1]. ED digunakan untuk menentukan kombinasi daya output pada tiap-tiap generator, agar didapatkan biaya pembangkitan yang minimal yang sesuai dengan permintaan beban. Dynamic Economic Dispatch (DED) adalah sebuah pengembangan dari ED, dimana pada DED besar bebannya selalu berubahberubah setiap periodenya (24 jam) [2].

Dalam pembangkitan tenaga listrik, ada beberapa cara yang dapat dilakukan, yang bertujuan untuk mengurangi total biaya pembangkitan, salah satunya adalah Demand Response (DR). DR adalah perubahan pola konsumsi konsumen dalam penggunaan listrik, perubahan ini diatur dengan sebuah program yang dinamakan Demand Response Program (DRP). Tujuan utama dari DRP ini adalah untuk menurunkan atau mengurangi biaya yang dibutuhkan untuk pembangkitan dan juga meningkatkan keandalan sistem [3]
Permasalahan yang akan dibahas pada penelitian ini yaitu, bagaimana cara pengimpelementasian incentive-based DRP (EDRP/DLC) pada permasalahan DED dan apa dampak pengimplementasian incentive-based DRP (EDRP/DLC) terhadap permasalahan DED.

Oleh karena itu, tujuan dari penelitian ini adalah mengetahui cara pengimplementasian incentive-based DRP (EDRP/DLC) pada permasalahan DED, dan juga mengetahui dampak pengimplementasian incentive-based DRP (EDRP/DLC) pada permasalahan DED.

Dalam penelitian ini, metode DRP yang akan digunakan adalah EDRP/DLC (emergency demand response program/direct load control), EDRP/DLC itu sendiri termasuk kedalam incentive-based DRP. Untuk menyelesaikan permasalahan yang sudah disebutkan diatas, penulis akan menggunakan metode particle swarm optimization (PSO).

\section{DASAR TEORI}

\section{A. Dynamic Economic Dispatch}

Dynamic Economic Dispatch (DED) adalah salah satu teknik optimasi dalam power systems yang digunakan untuk mendapatkan kombinasi daya output yang paling optimal atau ekonomis dari tiap generator selama periode tertentu. DED merupakan pengembangan lanjutan dari Economic Dispatch (ED), dimana pada ED, level beban yang ada cuma satu, sedangkan pada DED, besar beban yang ada selalu berubah-ubah setiap periodenya ( 24 jam), sehingga cost function dari setiap generator adalah sebagai berikut [6]:

$$
\begin{gathered}
C=\min \sum_{t=1}^{T} \sum_{j=1}^{N} F_{j t}\left(P_{j t}\right) \\
F_{j t}\left(P_{j t}\right)=a_{j t}+b_{j t}\left(P_{j t}\right)+c_{j t}\left(P_{j t}^{2}\right)
\end{gathered}
$$

Dimana:

$$
\begin{array}{ll}
C & : \text { total biaya pembangkitan }(\$) \\
F_{j} & : \text { cost function generator ke- } j \\
P_{j} & : \text { daya yang dibangkitkan oleh generator ke- } j \\
& \text { (MW) } \\
a, b, \text { dan } c & : \text { koefisien biaya generator ke- } j \\
N & : \text { jumlah generator } \\
T & : \text { jumlah periode waktu (jam) }
\end{array}
$$

Batasan-Batasan:

\section{Equality Constraint}

Dalam equality constraint, jumlah total daya yang dibangkitkan oleh generator harus sama dengan jumlah permintaan beban ditambah dengan rugi-rugi transmisinya, persamaannya adalah sebagai berikut [5]: 


$$
P_{G}=P_{D}+P_{\text {loss }}
$$

Tetapi, pada tugas akhir ini rugi-rugi transmisi diabaikan, sehingga persamaannya menjadi sebagai berikut:

$$
P_{G}=P_{D}
$$

Dimana:

$P_{G}:$ total daya dari semua pembangkit / generator (MW)

$P_{D}$ : total daya yang dibutuhkan beban (MW)

2. Inequality Constraint

Dalam batasan inequality constraint ini, daya yang dibangkitkan oleh setiap generator harus berada diantara batas daya minimum dan batas daya maksimum yang dimiliki oleh generator tersebut yang digambarkan seperti persamaan berikut:

$$
P_{G_{j}} \min \leq P_{G} \leq P_{G_{j}} \max
$$

Dimana:

$P_{G_{j}} \quad$ : total daya yang dibangkitkan oleh generator ke- $j$ (MW)

3. Incentive Limit

Batasan untuk nilai incentive yang adalah sebagai berikut [2]:

$$
\operatorname{inc}(t)^{\min } \leq \operatorname{inc}(t) \leq \operatorname{inc}(t)^{\max }
$$

Untuk nilai dari inc $(t)^{\mathrm{min}}$ adalah $0.1 x P_{0}(t)$ dan nilai dari $\operatorname{inc}(t)^{\max }$ adalah $10 x P_{0}(t)$.

Dimana:

inc $(t)^{\text {min }}$ : nilai minimum dari incentive (\$/MWh)

inc $(t) \quad$ : nilai incentive (\$/MWh)

$\operatorname{inc}(t)^{\max }:$ nilai maksimum dari incentive (\$/MWh)

$P_{0}(t) \quad$ : initial electricity price $(\$ / \mathrm{MWh})$

4. Ramp Rate Limit

Ramp rate limit adalah Batasan untuk perubahan daya untuk setiap generator pada setiap periodenya (per jam). Batasan ini digambarkan dengan persamaan berikut [6]:

$$
\begin{aligned}
& P_{j t}-P_{j}^{t-1} \leq U R_{j} \\
& P_{j}^{t-1}-P_{j t} \leq D R_{j}
\end{aligned}
$$

Dimana:

$P_{j t}, P_{j}^{t-1}$ : daya yang dibangkitkan generator ke- $j$ pada waktu ke- $t$ (MW)

$U R_{j} \quad$ : batas kenaikan daya generator ke-j

$D R_{j} \quad$ : batas penurunan daya generator ke-j

Persamaan (7) adalah batasan apabila daya yang dibangkitkan oleh generator mengalami kenaikan, sedangkan persamaan (8) adalah batasan apabila daya yang dibangkitkan mengalami penurunan. Dengan memperhatikan ramp rate limit yang sudah disebutkan, maka batasan $P_{\max }$ dan $P_{\text {min }}$ untuk periode selanjutnya berubah menjadi sebagai berikut [8]:

$$
\begin{aligned}
& P_{j} \min (t+1)=\max \left(P_{j} \min , P_{j t}-\text { rampdown }\right) \\
& P_{j} \max (t+1)=\min \left(P_{j} \max , P_{j t}+\text { rampup }\right)
\end{aligned}
$$

\section{B. Demand Response}

Demand Response (DR) merupakan perubahan perilaku konsumen dalam penggunaan listrik dari pola konsumsi normal atau awal yang kemudian berubah sesuai dengan perubahan harga listrik dari waktu ke waktu, atau pemberian reward berupa incentive apabila konsumen tersebut bersedia untuk mengurangi penggunaan listriknya [3]. DR ini dapat memberikan keuntungan bagi pihak konsumen maupun pihak pembangkit karena efek dari DR ini salah satunya adalah untuk mengurangi beban puncak sehingga akan mengurangi biaya pembangkitan, sedangkan keuntungan bagi pihak konsumen adalah pihak konsumen akan mendapatkan incentive [3].

Perubahan penggunaan listrik ini diatur dengan menggunakan program yang dinamakan demand response program (DRP). Ada beberapa cara yang dapat dilakukan oleh konsumen yang berpartisipasi di dalam DRP untuk mengubah pola konsumsi listriknya, yaitu dengan mengurangi konsumsi energi listrik dengan strategi pengurangan beban, strategi pengurangan beban ini dapat berupa pemberian incentive kepada konsumen agar supaya konsumen bersedia untuk mengurangi konsumsi energi listrik mereka pada suatu periode tertentu (peak hour) atau dengan memindahkan konsumsi energi listrik mereka ke periode waktu yang berbeda (periode waktu dengan harga yang lebih murah).

\section{Demand Response Program}

Demand response programs dapat dibagi menjadi tiga jenis program yaitu rate-based or price DR program, incentive or event-based DR programs, dan demand reduction bids [3].

1. Rate-Based DR Program:

- TOU (Time of Use Rates)

- CPP (Critical Peak Pricing)

- RTP (Real-time Pricing)

2. Incentive or Event-Based DR Program:

- Direct Load Control (DLC)

- Emergency Demand Response Programs (EDRP)

- Capacity Market Programs

- Interruptible / Curtailable

- Ancillary Services Market Programs

3. Demand Reduction Bids:

- Demand Bidding / Buyback Programs

\section{PENERAPAN INCENTIVE-BASED DEMAND RESPONSE PROGRAM DAN PARTICLE SWARM OPTIMIZATION PADA DYNAMIC ECONOMIC DISPATCH}

\section{A. Penerapan Incentive-Based Demand Response Program}

Cost Function untuk setiap generator pada permasalahan DED dinyatakan dengan fungsi kuadrat sebagai berikut:

$$
\begin{gathered}
C=\min \sum_{t=1}^{T} \sum_{j=1}^{N} F_{j t}\left(P_{j t}\right) \\
F_{j t}\left(P_{j t}\right)=a_{j t}+b_{j t}\left(P_{j t}\right)+c_{j t}\left(P_{j t}^{2}\right)
\end{gathered}
$$

Untuk biaya dari pengimplementasian EDRP/DLC adalah sebagai berikut [2]:

$$
C_{D R}(t)=\left(d_{0}(t)-d(t)\right) x \operatorname{inc}(t)
$$

Dimana:

$C_{D R}(t)$ : biaya pengimplementasian $\operatorname{EDRP} / \mathrm{DLC}(\$ / \mathrm{h})$

$d_{0}(t)$ : beban awal (MW)

$d(t)$ : beban setelah pengimplementasian EDRP/DLC (MW) inc $(t)$ : incentive (\$/MWh)

Maka, dengan menambahkan persamaan (13) ke persamaan (11), objective function dari permasalahan DED dengan mempertimbangkan incentive-based DRP adalah sebagai berikut:

$C=\sum_{t=1}^{T}\left\{\left[\sum_{j=1}^{N} a_{j t}+b_{j t}\left(P_{j t}\right)+c_{j t}\left(P_{j t}^{2}\right)\right]+C_{D R}(t)\right\}$

\section{B. Responsive Load Economic Model}

Economic load model merepresentasikan perubahan permintaan beban oleh konsumen yang dipengaruhi oleh perubahan harga listrik, incentive, dan juga penalty yang akan 
diberikan kepada konsumen apabila konsumen tersebut melakukan pelanggaran. Economic load model digambarkan dengan persamaan sebagai berikut [2]:

$$
d(t)=d_{0}(t) x\left\{1+\sum_{t^{\prime}=1}^{24} E\left(t, t^{\prime}\right) x \frac{\left[p\left(t^{\prime}\right)-p_{0}\left(t^{\prime}\right)+i n c\left(t^{\prime}\right)-p e n\left(t^{\prime}\right]\right.}{p_{0}\left(t^{\prime}\right)}\right\}
$$

Dimana, $d(t)$ dan $d_{0}(t)$ adalah permintaan beban sesudah pengimplementasian dan sebelum pengimplementasian demand response program, $p\left(t^{\prime}\right)$ dan $p_{0}\left(t^{\prime}\right)$ adalah electricity price dan initial electricity price pada periode $t^{\prime}$, $E\left(t, t^{\prime}\right)$ adalah nilai elasticity dimana elasticity didefinisikan sebagai sensitivitas permintaan sehubungan dengan harga listrik.

Elasticity dapat dibagi menjadi 2, yaitu self-elasticity dan cross-elasticity. Self-elasticity merepresentasikan sensitivitas konsumen pada periode $\mathrm{t}$ terhadap perubahan harga, pemberian insentif atau nilai penalty pada periode $\mathrm{t}$ dan nilainya selalu negatif, sedangkan untuk cross-elasticity merepresentasikan sensitivas konsumen pada periode $\mathrm{t}$, terhadap perubahan harga, pemberian insentif atau nilai penalty pada periode $\mathrm{j}$ dan nilainya selalu positif [7]. Nilai dari self and cross elasticity dapat dilihat pada Tabel 1 [2].

Tabel 1

\begin{tabular}{|c|c|c|c|}
\hline & Peak & Off-peak & Valley \\
\hline Peak & -0.10 & 0.016 & 0.012 \\
\hline Off-peak & 0.016 & -0.10 & 0.01 \\
\hline Valley & 0.012 & 0.01 & -0.10 \\
\hline
\end{tabular}

Terdapat 3 faktor yang dapat digunakan untuk mengukur performansi dari pengimplementasian demand response program, faktor-faktor tersebut adalah sebagai berikut:

\section{Load Factor}

Load factor adalah rasio dari nilai beban rata-rata terhadap nilai beban puncak pada suatu periode tertentu. Semakin tinggi nilai dari load factor ini, maka semakin ekonomis juga kinerja dari pembangkit [4]. Nilai ideal dari faktor ini adalah $100 \%$ yang berarti beban selalu konstan dan tidak berubah dari waktu ke waktu. Load factor dinyatakan dengan persamaan berikut:

Load factor $(\%)=100 \times\left(\frac{\sum_{t=1}^{T} d(t)}{T \times d^{\max }(t)}\right)$

2. Peak to Valley

Peak to valley adalah faktor yang menunjukkan nilai rasio dari jarak antara peak dengan valley. Peak to valley dinyatakan dengan persamaan berikut:

Peak to valley $(\%)=100 \times\left(\frac{d^{\max }(t)-d^{\min }(t)}{d^{\max }(t)}\right)$

3. Peak Compensate

Setelah pengimplementasian demand response program, nilai dari beban puncak akan mengalami penurunan, oleh karena itu, faktor ini berfungsi untuk menunjukkan seberapa besar penurunan dari beban puncak tersebut. Peak compensate dinyatakan dengan persamaan berikut:

$$
\text { Peak compensate }(\%)=100 \times\left(\frac{d_{0}^{\max }(t)-d^{\max }(t)}{d_{0}^{\max }(t)}\right)
$$

\section{Particle Swarm Optimization}

Particle Swarm Optimization (PSO) merupakan algoritma optimasi yang berbasis kecerdasan buatan yang terinpirasi dari perilaku sekelompok burung yang sedang mencari sumber makanan. Algoritma PSO ini dikemukakan oleh J. Kennedy pada tahun 1995.

Setiap individu yang ada dalam sekelompok burung tersebut disebut sebagai partikel, sedangkan untuk populasi dari burung tersebut disebut swarm. Tempat makanan yang terbaik, dianggap sebagai nilai optimal. Jika partikel menemukan sumber makanan, maka partikel yang lain juga akan bergerak menuju sumber makanan tersebut, dan apabila sumber makanan yang baru yang lebih baik dari sebelumnya ditemukan, maka partikel akan mengubah arah ke arah letak makanan yang lebih baik.

Dalam proses ketika burung mencari makanan ini, setiap burung akan mengingat lokasi makanan yang telah mereka temukan, lokasi dengan nilai fitness terbaik disebut dengan Pbest, dan juga dalam sekelompok burung yang terdiri dari beberapa burung, akan ditentukan lokasi yang memiliki nilai fitness Pbest terbaik yang kemudian akan dijadikan sebagai Gbest [9]. [9]:

Persamaan untuk kecepatan partikel adalah sebagai berikut

$V_{i}^{k+1}=\omega V_{i}^{k}+c_{1}$ rand $_{1} x\left(\right.$ Pbest $\left._{i}^{k}-x_{i}^{k}\right)+c_{2}$ rand $_{2} x\left(\right.$ Gbest $\left.^{k}-x_{i}^{k}\right)$

(19)

Sedangkan untuk persamaan posisi partikelnya adalah sebagai berikut:

$$
X_{i}^{k+1}=x_{i}^{k}+V_{i}^{k+1}
$$

Untuk $V_{i}^{k}$ merepresentasikan kecepatan partikel $i$ pada saat iterasi $\mathrm{k}, \omega$ adalah inertia weight factor, $c_{1} c_{2}$ adalah acceleration coefficients, sedangkan untuk rand $_{1}$ rand $_{2}$ menyatakan nilai acak antara 0 sampai $1, \quad x_{i}^{k}$ merepresentasikan posisi partikel $i$ pada saat iterasi $k$, Pbest $_{i}^{k}$ adalah posisi terbaik partikel $i$ pada saat iterasi $k$, dan yang terakhir Gbest $^{k}$ merupakan posisi terbaik sebuah populasi di iterasi $k$. Untuk persamaan inertia weight adalah sebagai berikut:

$$
w_{i t}=w_{\max }-\frac{\left(w_{\max }-w_{\min }\right) * I t}{I t_{\max }}
$$

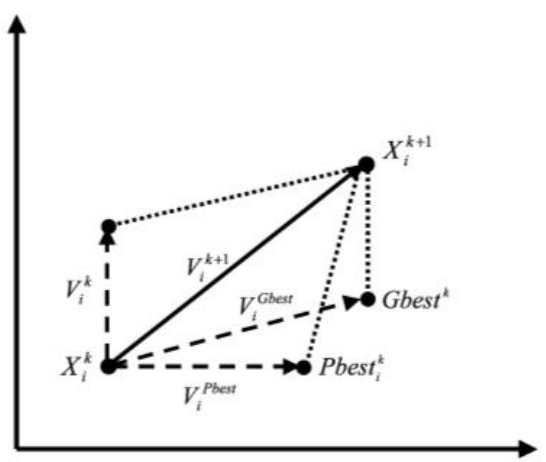

Gambar 1. Konsep Particle Swarm Optimization

\section{Penerapan PSO}

Berikut adalah parameter-parameter PSO yang akan digunakan pada setiap studi kasus di tugas akhir ini. Parameter tersebut adalah sebagai berikut:

- Jumlah Populasi : 100

- Jumlah Variabel : 6

- Iterasi Maksimal : 200

- $\mathrm{C} 1 \quad: 2$

- $\mathrm{C} 2 \quad: 2$

- $\quad \operatorname{Inertia}(w) \quad: 0.4-0.9$

Populasi terdiri dari sekumpulan variabel atau partikel. Variabel adalah parameter yang akan di optimasi pada tugas akhir ini. Iterasi maksimal adalah banyaknya proses pengulangan, sedangkan untuk $\mathrm{c} 1$ dan c2 yang merupakan social dan cognitive constant adalah nilai konstanta yang telah di tentukan di dalam algoritma PSO ini. Untuk 0.4 dan 0.9 adalah nilai dari $w_{\min }$ dan $w_{\max }$, nilai ini dibutuhkan untuk mencari nilai inertia weight pada persamaan (21). 


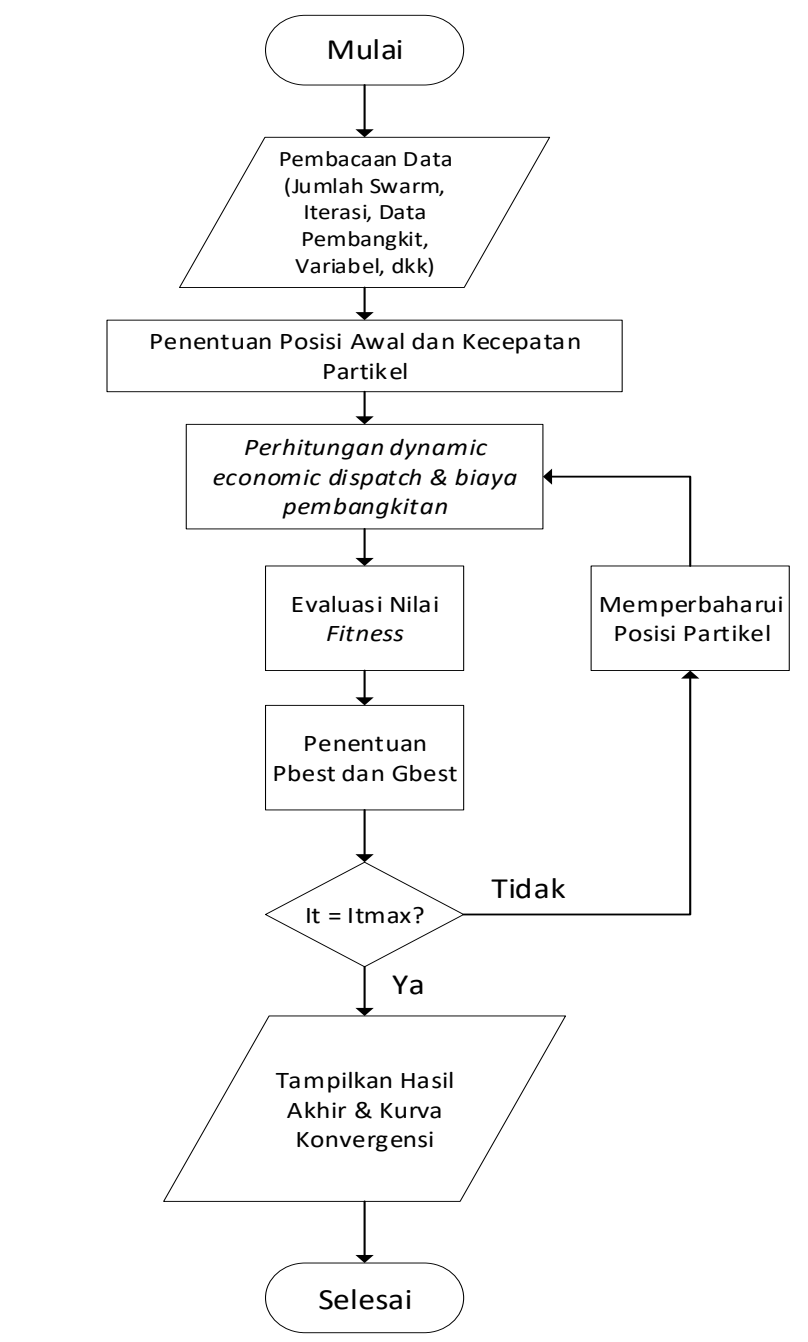

Gambar 2. Flowchart PSO

E. Algoritma Pengerjaan Dynamic Economic Dispatch Mempertimbangkan Demand Response Menggunakan Particle Swarm Optimization

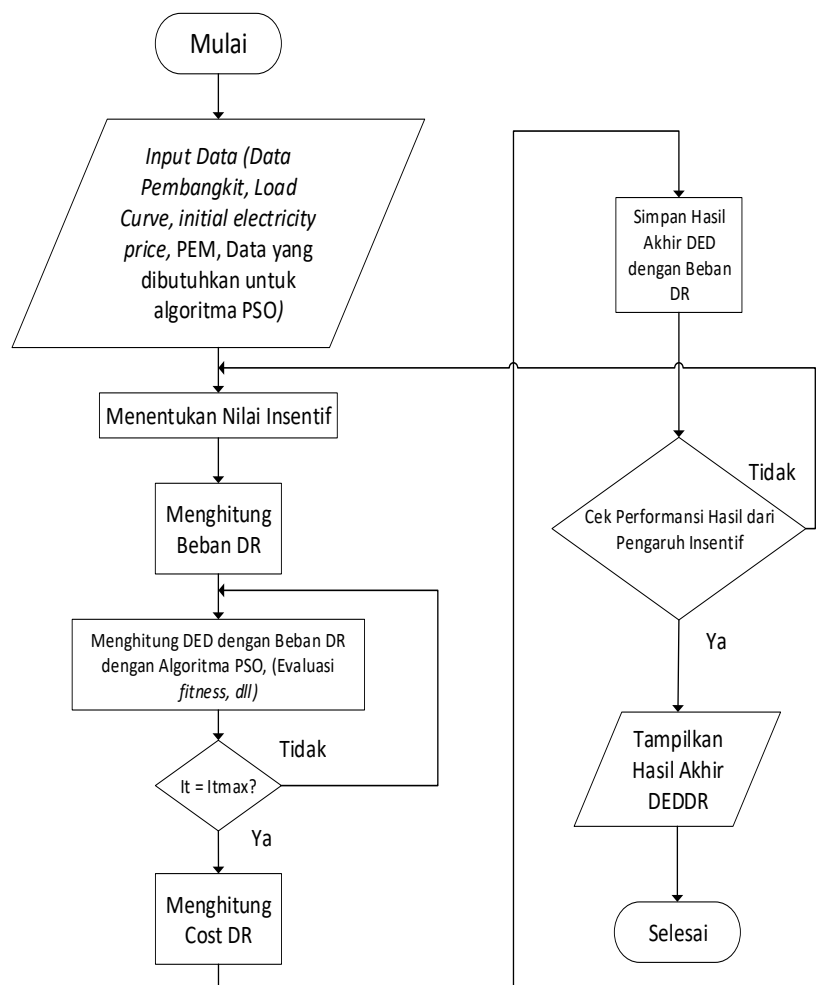

Gambar 3. Flowchart DED dengan DRP Menggunakan PSO

\section{HASIL DAN ANALISIS}

\section{A. Sistem IEEE 30 Bus}

Berikut ini adalah data sistem pembangkit yang digunakan [10]:

Tabel 2.

Data Cost Function

\begin{tabular}{cccc}
\hline \hline \multirow{2}{*}{ No. Bus } & \multicolumn{3}{c}{ Koefisien Biaya } \\
\cline { 2 - 4 } & $\mathrm{a}$ & $\mathrm{b}$ & $\mathrm{c}$ \\
\hline 1 & 0 & 2 & 0.00375 \\
\hline 2 & 0 & 1.75 & 0.0175 \\
\hline 5 & 0 & 1 & 0.0625 \\
\hline 8 & 0 & 3.25 & 0.00834 \\
\hline 11 & 0 & 3 & 0.025 \\
\hline 13 & 0 & 3 & 0.025 \\
\hline \hline
\end{tabular}

Tabel 3.

Data Batasan Kemampuan Generator

\begin{tabular}{lllll}
\hline \hline No. Bus & Pmin (MW) & Pmax (MW) & DR (MW) & UR (MW) \\
\hline 1 & 50 & 200 & 20 & 20 \\
2 & 20 & 80 & 20 & 20 \\
5 & 15 & 50 & 5 & 5 \\
8 & 10 & 35 & 5 & 5 \\
11 & 10 & 30 & 5 & 5 \\
13 & 12 & 40 & 5 & 5 \\
\hline \hline
\end{tabular}

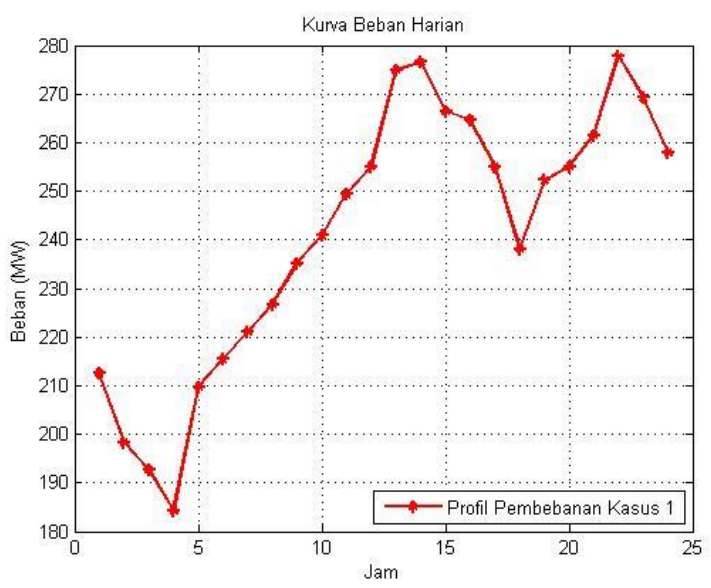

Gambar 4. Profil Pembebanan Sistem IEEE 30 Bus (Kasus 1)

Profil pembebanan sistem IEEE 30 Bus dibagi menjadi sebagai berikut:

1. Peak period (jam 10 - jam 16 \& jam 20 - jam 24)

2. Off-peak period (jam 6 - jam $9 \&$ jam 17 - jam 19)

3. Valley period (jam $1-$ jam 5)

Parameter incentive-based DRP yang digunakan:

- Incentive $($ peak period $)=0.8 \$ / \mathrm{MWh}$ (Asumsi)

- $E\left(t, t^{\prime}\right)$ (Self and Cross Elasticity) $=$ Tabel 3.1

- $p_{0}\left(t^{\prime}\right)$ (Initial Electricity Price) $=3 \$ / \mathrm{MWh}$ (Asumsi harga listrik pada peak hour)

- $p\left(t^{\prime}\right)$ (Electricity Price) $=3.5 \$ / \mathrm{MWh}$ (Diasumsikan harga listrik pada peak hour mengalami perubahan)

- Penalty $=0 \$ / \mathrm{MWh}(\mathrm{EDRP} / \mathrm{DLC}$ dilaksanakan secara sukarela sehingga tidak ada nilai penalty)

Berikut adalah studi kasus yang akan dilakukan pada penelitian ini:

1. Studi Kasus 1

Pada studi kasus ini akan diperlihatkan hasil perhitungan

DED tanpa implementasi incentive-based DRP

2. Studi Kasus 2

Pada studi kasus ini akan diperlihatkan hasil perhitungan dengan DED dengan implementasi incentive-based DRP dengan nilai elasticity seperti pada Tabel 1.

3. Studi Kasus 3 
Pada studi kasus ini akan diperlihatkan hasil perhitungan dengan DED dengan implementasi incentive-based DRP nilai elasticity sebesar 0.5 kali dari Tabel I.

4. Studi Kasus 4

Pada studi kasus ini akan diperlihatkan hasil perhitungan dengan DED dengan implementasi incentive-based DRP dengan nilai elasticity sebesar 2 kali dari Tabel I.

Berikut adalah hasil yang didapat:

Tabel 4.

Perbandingan Permintaan Beban Setiap Kasus

\begin{tabular}{ccccc}
\hline \hline \multirow{2}{*}{ Jam } & $\begin{array}{c}\text { Beban Kasus } \\
1(\mathrm{MW})\end{array}$ & $\begin{array}{c}\text { Beban Kasus } \\
2(\mathrm{MW})\end{array}$ & $\begin{array}{c}\text { Beban Kasus } \\
\text { 3 }(\mathrm{MW})\end{array}$ & $\begin{array}{c}\text { Beban Kasus } \\
4(\mathrm{MW})\end{array}$ \\
\hline 1 & 212.55 & 213.66 & 213.10 & 214.76 \\
2 & 198.38 & 199.41 & 198.89 & 200.44 \\
3 & 192.712 & 193.71 & 193.21 & 194.72 \\
4 & 184.21 & 185.17 & 184.69 & 186.13 \\
5 & 209.716 & 210.81 & 210.26 & 211.89 \\
6 & 215.384 & 216.88 & 216.13 & 218.37 \\
7 & 221.052 & 222.58 & 221.82 & 224.12 \\
8 & 226.72 & 228.29 & 227.51 & 229.86 \\
9 & 235.222 & 236.85 & 236.04 & 238.48 \\
10 & 240.89 & 230.45 & 235.67 & 220.01 \\
11 & 249.392 & 238.59 & 243.99 & 227.78 \\
12 & 255.06 & 244.01 & 249.53 & 232.96 \\
13 & 274.898 & 262.99 & 268.94 & 251.07 \\
14 & 276.5984 & 264.61 & 270.61 & 252.63 \\
15 & 266.396 & 254.85 & 260.63 & 243.31 \\
16 & 264.6956 & 253.23 & 258.96 & 241.76 \\
17 & 255.06 & 256.83 & 255.95 & 258.60 \\
18 & 238.056 & 239.71 & 238.89 & 241.36 \\
19 & 252.226 & 253.97 & 253.10 & 255.72 \\
20 & 255.06 & 244.01 & 249.53 & 232.96 \\
21 & 261.5782 & 250.24 & 255.91 & 238.91 \\
22 & 277.732 & 265.70 & 271.72 & 253.66 \\
23 & 269.23 & 257.56 & 263.39 & 245.90 \\
24 & 257.894 & 246.72 & 252.31 & 235.54 \\
Total & 5790.71 & 5670.82 & 5730.77 & 5550.93 \\
\hline \hline
\end{tabular}

Tabel 5.

Perbandingan Permintaan Beban Setiap Kasus

\begin{tabular}{ll}
\hline \hline Kasus & Pengurangan Beban (MW) \\
\hline 1 & - \\
2 & 119.8922 \\
3 & 59.94 \\
4 & 239.78 \\
\hline \hline
\end{tabular}

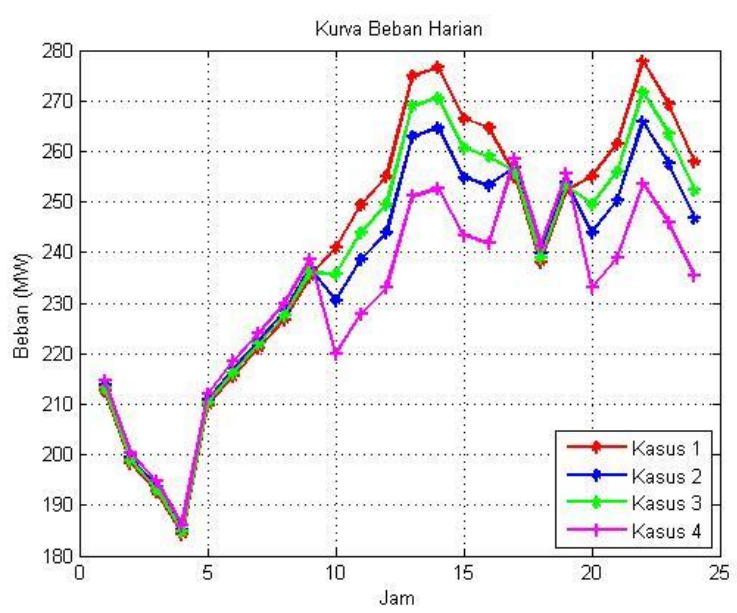

Gambar 5. Perbandingan Profil Pembebanan (Kasus 1-4)

Tabel 6.

Perbandingan Total Biaya Pembangkitan

\begin{tabular}{|c|c|c|c|}
\hline Kasus & $\begin{array}{c}\text { Total Biaya } \\
\text { Pembangkitan }(\$)\end{array}$ & $\begin{array}{c}\text { Total Incentive } \\
\text { (\$) }\end{array}$ & $\begin{array}{c}\text { Total Biaya } \\
\text { (\$) }\end{array}$ \\
\hline 1 & 15264.11 & - & 15264.11 \\
\hline 2 & 14893.83 & 109.19 & 15003.02 \\
\hline 3 & 15064.72 & 54.6 & 15119.32 \\
\hline 4 & 14549.23 & 218.36 & 14767.59 \\
\hline
\end{tabular}

Tabel VII.

Perbandingan Performansi DRP

\begin{tabular}{crrr}
\hline \hline Kasus & LF $(\%)$ & PV $(\%)$ & PC $(\%)$ \\
\hline 1 & 86.87 & 33.67 & - \\
2 & 88.92 & 30.30 & 4.33 \\
3 & 87.88 & 32.02 & 2.17 \\
4 & 89.44 & 28.02 & 6.99 \\
\hline \hline
\end{tabular}

Dari hasil simulasi yang didapat, dapat dilihat bahwa, incentive-based DRP dapat mengurangi total biaya pembangkitan (total biaya kasus 2, 3, dan 4 mengalami penurunan), meskipun dengan pengimplementasian ini menghasilkan biaya yang baru (biaya pengimplementasian), akan tetapi total biaya yang dihasilkan (total biaya pembangkitan ditambah total biaya pengimplementasian) setelah pengimpelementasian incentive-based DRP ini lebih murah daripada total biaya sebelum pengimplementasian. dan dapat dilihat juga, semakin besar nilai elasticity atau sensitivitas dari konsumen maka akan semakin besar pula biaya pengimplementasiannya (total incentive). Pada tabel VII pun dapat dilihat bahwa, efek dari pengimplementasian ini, adalah dapat meningkatkan load factor, menurunkan nilai peak to valley (jarak antara beban valley dan peak semakin mengecil), dan juga didapatkan pengurangan beban pada saat peak period (peak compensate nya bertambah).

\section{KESIMPULAN/RINGKASAN}

Berdasarkan hasil simulasi dari penelitian permasalahan DED dengan pengimplementasian incentive-based DRP (EDRP/DLC) yang diselesaikan dengan menggunakan metode algotritma PSO pada sistem IEEE 30 Bus, didapatkan beberapa kesimpulan sebagai berikut:

1. Hasil simulasi menunjukkan bahwa, setelah dilakukan pengimplementasian, pada kasus 2 terjadi penurunan biaya sebesar \$261.09, pada kasus 3 terjadi penurunan biaya sebesar \$144.79, dan juga pada kasus 4 terjadi penurunan biaya sebesar \$496.52. Hal ini menunjukkan bahwa pengimplementasian incentive-based DRP pada permasalahan DED menghasilkan biaya pembangkitan yang lebih murah dari sebelum pengimplementasian.

2. Dari hasil simulasi, total incentive yang dihasilkan pada kasus 2 adalah sebesar \$109.19, pada kasus 3 sebesar \$54.6, dan pada kasus 4 sebesar \$218.36. Hal ini menunjukkan bahwa, semakin tinggi sensitivitas (elasticity) dari pada konsumen, maka semakin tinggi juga total incentive yang harus diberikan, dan begitu juga sebaliknya.

3. Incentive-based DRP (EDRP/DLC) merupakan metode yang menguntungkan bagi kedua-belah pihak, yaitu bagi pihak konsumen dan juga bagi pihak perusahaan pembangkitan energi listrik. Dapat dikatakan menguntungkan kedua-belah pihak karena selain menghasilkan biaya pembangkitan yang lebih murah yang merupakan keuntungan bagi pihak perusahaan pembangkitan energi listrik, pihak konsumen juga mendapatkan keuntungan berupa incentive.

\section{DAFTAR PUSTAKA}

[1] A. J. Wood dan B. F. Wollenberg, Power generation, operation, and control, 2. ed. New York, NY: Wiley, 1996.

[2] H. Abdi, E. Dehnavi, dan F. Mohammadi, "Dynamic Economic Dispatch Problem Integrated With Demand Response (DEDDR) Considering Non-Linear Responsive Load Models," IEEE Trans. Smart Grid, vol. 7, no. 6, hlm. 2586-2595, Nov 2016. 
[3] P. Siano, "Demand response and smart grids-A survey," Renew. Sustain. Energy Rev., vol. 30, hlm. 461-478, Feb 2014.

[4] H. Saadat, Power system analysis. Boston: WCB/McGraw-Hill, 1999.

[5] J.-B. Park, K.-S. Lee, J.-R. Shin, dan K. Y. Lee, “A Particle Swarm Optimization for Economic Dispatch With Nonsmooth Cost Functions," IEEE Trans. Power Syst., vol. 20, no. 1, hlm. 34-42, Feb 2005.

[6] G. K. Gupta dan S. Goyal, "Particle swarm intelligence based dynamic economic dispatch with daily load patterns including valve point effect," 2017, hlm. 83-87.

[7] H. A. Aalami, M. P. Moghaddam, dan G. R. Yousefi, "Demand response modeling considering Interruptible/Curtailable loads and capacity market programs," Appl. Energy, vol. 87, no. 1, hlm. 243250, Jan 2010.

[8] Ferdiyansah, Teguh. Dynamic Economic Dispatch Dengan Kurva Biaya Pembangkitan Yang Tidak Smooth Menggunakan Particle Swarm Optimization. Tugas Akhir Jurusan Teknik Elektro ITS. 2013

[9] Nur Wahyudi, Afif. Dynamc Optimal Power Flow (DOPF) dengan Kurva Biaya Pembangkitan Tidak Mulus Menggunakan Particle Swarm Optimization (PSO). Tugas Akhir Jurusan Teknik Elektro ITS 2013

[10] Kharisma, Hilmy. Dynamic Optimal Power Flow Mempertimbangkan Valve Point Effect Menggunakan Modified Honey Bee Mating Optimisation. Tugas Akhir Departemen Teknik Elektro ITS 2017 